\title{
Cobalt Ferrite Nanoparticles: An Innovative Approach for Enhanced Oil Recovery Application
}

\author{
Noorhana Yahya, a , Muhammad Kashif ${ }^{2}$, Nadeem Nasir ${ }^{2}$, \\ Majid Niaz Akhtar ${ }^{2}$ and Noorasikin Mohd Yusof ${ }^{2}$ \\ ${ }^{1}$ Fundamental and Applied Sciences Department \\ ${ }^{2}$ Electrical and Electronic Engineering Department \\ Universiti Teknologi PETRONAS, 31750 Bandar Seri Iskandar, Tronoh, Perak, Malaysia \\ anoorhana_yahya@petronas.com.my
}

Keywords: nanoparticles, ferrite magnetic feeders, enhanced oil recovery, nanofluid, core rock samples, glass beads

\begin{abstract}
This paper describes the synthesis of cobalt ferrite $\left(\mathrm{CoFe}_{2} \mathrm{O}_{4}\right)$ nanoparticles and their application in enhanced oil recovery. Cobalt ferrite $\left(\mathrm{CoFe}_{2} \mathrm{O}_{4}\right)$ nanoparticles were used as ferrite magnetic feeders with antenna to improve the magnetic field strength and cobalt ferrite nanofluid to improve oil recovery. Cobalt ferrite $\left(\mathrm{CoFe}_{2} \mathrm{O}_{4}\right)$ nanoparticles were synthesized by sol-gel method. These nanoparticles were then characterized by using X-ray diffractometer (XRD) and Field Emission Scanning Electron Microscope (FESEM). Cobalt ferrite nanoparticles annealed at $600^{\circ} \mathrm{C}$, the particle size is $51.17 \mathrm{~nm}$ and $26 \mathrm{~nm}$ as determined by XRD and FESEM, respectively while for the sample annealed at $800^{\circ} \mathrm{C}$, the particle size is $62 \mathrm{~nm}$ as determined by XRD and $60 \mathrm{~nm}$ as determined by FESEM. Magnetic measurement results show that initial permeability of cobalt ferrite powder increased and relative loss factor decreased at high frequency. In order to improve the oil recovery, nanoparticles were used in two different experiments. In the first experiment, nanoparticles were used as magnetic feeders with an antenna to improve the magnetic field strength. In the second experiment, nanoparticles were used as nanofluids. Results show that the antenna with magnetic feeders increases the magnetic field strength by $0.94 \%$ as compared to antenna without magnetic feeders in the water, and by $5.90 \%$ in the air. Magnitude versus offset (MVO) study of antenna with magnetic feeders shows an increase in magnetic field strength of $275 \%$ as compared to antenna without magnetic feeders. It is found that antenna with magnetic feeders was able to recover $29.50 \%$ and $20.82 \%$ of original oil in place (OOIP) in core rock samples A-1 and A2 respectively. The use of cobalt ferrite nanoparticles as a nanofluid with electromagnetic waves yielded a higher recovery of residual oil in place (ROIP) which is $31.58 \%$ as compared to $8.70 \%$ when it was used as nanofluid alone. It is investigated that due to absorption of electromagnetic waves by cobalt ferrite nanoparticles the oil viscosity reduces which increase the oil recovery. It can be concluded that the synthesised cobalt ferrite $\left(\mathrm{CoFe}_{2} \mathrm{O}_{4}\right)$ nanoparticles can be potentially used for enhanced oil recovery in future.
\end{abstract}

\section{Introduction}

During the past years varieties of enhanced oil recovery (EOR) methods have been applied in the field to increase oil production. These methods can be divided into three general areas viz. gas injection, chemical methods and thermal methods. Gas injection method consists of $\mathrm{CO}_{2}$ and $\mathrm{N}_{2}$ injection methods, while chemical methods consist of surfactant, surfactant with polymer, surfactant with foam and thermal methods consist of conventional steam injection, steam assisted gravity drainage, cyclic injection, and in-situ combustion. Thermal recovery methods are used to increase the oil recovery by raising the temperature of the reservoir, and reducing the oil viscosity [1]. In these methods, the most famous method for oil recovery is steam injection method. However, there are many cases such as very deep formation, thin pay-zones, low permeability formations, and reservoir heterogeneity where steam injection method is not feasible [2,3]. Electromagnetic heating 
of these reservoirs can be an alternative method for steam injection [2, 4]. Electromagnetic heating in the reservoir can be produced by two ways namely high frequency (Radio and Microwave), and low frequency also known as resistive heating. The electrical energy from the electromagnetic waves transfers to the dielectric and resistive materials in the form of heat and reduces the oil viscosity, which as a result increases the oil mobility. At high frequency, the amount of energy absorbed by the material depends on their electrical property which is related to absorption of the electromagnetic waves. This property changes with temperature and water saturation. The electromagnetic waves cause a change in the dipole alignment of the molecules, which produces heat thus heating the surrounding environment. The power dissipation due to high frequency electromagnetic can be expressed by the relation $\mathrm{P}=\sigma \mathrm{E}^{2}$. However, when the electrical energy is in low frequency $(50 \mathrm{~Hz})$, electromagnetic waves cause resistive heating to take place and power dissipation becomes $\mathrm{P}=\mathrm{I}^{2} \mathrm{R}[5,6]$.

Many researchers have studied both theoretically and experimentally, the use of electromagnetic method for enhanced oil recovery. Bridges et al. developed a model for electromagnetic heating of a single-well [7]. In this model, finite difference reservoir simulator was used for the resulting spatial heat distribution when electromagnetic source was considered constant with time and it was reported that an increased in the oil production rate in the order of 80 to $25 \%$ as compared to initial production. Soliman et al. developed a model for oil flow by microwave heating [8]. The analytical and numerical solutions for microwave problems were obtained after assuming specific reservoir dimensions and oil properties. Sresty et al. used radio frequency electromagnetic waves both in the laboratory and in the field for the recovery of bitumen from tar sand deposits [9]. They obtained 50$80 \%$ recovery of bitumen and they also showed that the process was economical and energy efficient. Chakma et al. presented a laboratory model for recovery of oil from thin pay zone by using electromagnetic waves combined with gas injection [10]. They observed minimum heat loss when electromagnetic heating was confined to oil bearing zone. They showed that salinity, oil viscosity, pressure, frequency, temperatures do influence the oil recovery and they obtained $45 \%$ recovery when combining electromagnetic waves with gas injection.

Nanoparticles exhibit potential for enhanced oil recovery applications because of their interfacial activity. Many researchers have studied the dispersion of aqueous nanoparticles and propagation of nanoparticles through porous media [11-17].Yu et al. studied the transport property of surfacetreated paramagnetic iron-oxide nanoparticles in sedimentary rocks [11]. The nanoparticles in different weight ratio were dispersed with different ionic strengths and $\mathrm{pH}$. Different surface treatments produced stable dispersions but different transport property. The results were analyzed in terms of surface charges, zeta potential, and van der Waals interaction between particles and rock.

Ferrite nanoparticles can be used as a heating source when they absorb electromagnetic waves. This heating of ferrite nanoparticles takes place due to hysteresis loss and relaxation loss in electromagnetic field [18-20]. The heat produced by nanoparticles depends on the frequency of the external electromagnetic field, the nature of the particles, and the particle surface modifications. Due to hysteresis loss, the heat generated $(\mathrm{P})$ by ferromagnetic particles is given by Eq.1,

$$
P=f \Delta U
$$

where $\mathrm{f}$ is the frequency and $\Delta \mathrm{U}$ is the area of the hysteresis loop in an applying electromagnetic field. Due to relaxation loss, heat generated $(\mathrm{P})$ by superparamagnetic particles is given by Eq.2,

$$
P=\pi \mu_{o} \chi f H^{2}
$$

where $f$ is the frequency, $\mathrm{H}$ is the magnetic field strength, $\chi$ is the imaginary part of the magnetic susceptibility, and $\mu_{\mathrm{o}}$, is the permeability of free space.

Due to self heating property, these ferrite nanoparticles have potential for applications in enhanced oil recovery process. Thus this work has been carried out with the objective to synthesize cobalt ferrite nanoparticles and to study their uses as ferrite magnetic feeders with an electromagnetic antenna and as nanofluid for enhanced oil recovery application. 


\section{Material and Methods}

Cobalt ferrite nanoparticles were synthesized by sol gel method. Two sets of experiments were conducted first set is using these nanoparticles as ferrite magnetic feeders with an antenna and second set is as nanofluid in enhanced oil application.

\section{Preparation of Cobalt Particles}

Cobalt (II) Nitrate Hexahydrate $\left[\mathrm{Co}\left(\mathrm{NO}_{3}\right)_{2} \cdot 6 \mathrm{H}_{2} \mathrm{O}\right]$ and Iron nitrate $\left[\left(\mathrm{Fe}\left(\mathrm{NO}_{3}\right)_{3} .9 \mathrm{H}_{2} \mathrm{O}\right)\right]$ were used as the raw materials. These raw materials were dissolved in an aqueous solution of $165 \mathrm{ml}$ of nitric acid $\left(\mathrm{HNO}_{3}\right)$. The solutions were stirred at $250 \mathrm{rpm}$ for 1 day, separately and then were mixed into one solution. The mixed solutions were stirred for another 1 day and then heated up gradually upto $70^{\circ} \mathrm{C}$ until gel-like solution was formed and the heating process was stopped immediately.

Then the gel-like solution was dried in an oven at $110^{\circ} \mathrm{C}$ for 10 days. Next the dried sample was crushed for 8 hours to obtain fine particles. The crushed powder was sintered at two temperatures, $600^{\circ} \mathrm{C}$ and $800^{\circ} \mathrm{C}$ separately for 4 hours, to obtain the required characteristics of ferrite powder. After the annealing process was completed, the samples were crushed again for 2 hours. The crystalline structure of cobalt ferrite was characterized by X-ray diffractometer (Bruker D8 advance). The morphology and grain size of the particles were measured by Field Emission Microscopy FESEM (SUPRA 55VP ZEISS).

The Cobalt ferrite powder was fabricated in the form of toroid in order to analyze the magnetic characterization. $0.5 \mathrm{~g}$ of Cobalt ferrite powder was mixed with one drop of polyvinyl alcohol (PVA) and was crushed for some time. The mixture was filled into a toroidal mould and pressed with $3000 \mathrm{~kg}$ or $1500 \mathrm{lb}$ load by using autopellet pressing machine. Finally, the toroid was then sintered at $1200 \mathrm{oC}$ for 6 hours. Initial permeability, Q-factor, and relative loss factor of toroids were calculated by Agilent impedance analyzer model $4294 \mathrm{~A}$ in the frequency range of $40 \mathrm{~Hz}$ to $110 \mathrm{MHz}$.

\section{Nanoparticles As Ferrite Magnetic Feeders With An Antenna and Nanofluid \\ Nanoparticles As Ferrite Magnetic Feeders}

An experimental study was conducted to evaluate the performance of curve twin dipole antenna with and without ferrite magnetic feeders and its use in enhanced oil recovery process. A curve twin dipole Aluminum antenna and four magnetic feeders in the form of toroids having 20 turns of copper wire and two different core samples were used in this study. The experiments were conducted at a laboratory scale model as shown in Fig.1. The heart of the setup is the reservoir like model consisting of a rectangular tank made of thick Perspex sheet of the following dimension $20 \mathrm{~cm} \times 30 \mathrm{~cm} \times 20 \mathrm{~cm}$. The tank was filled with brine of $10000 \mathrm{ppm}$ salinity.

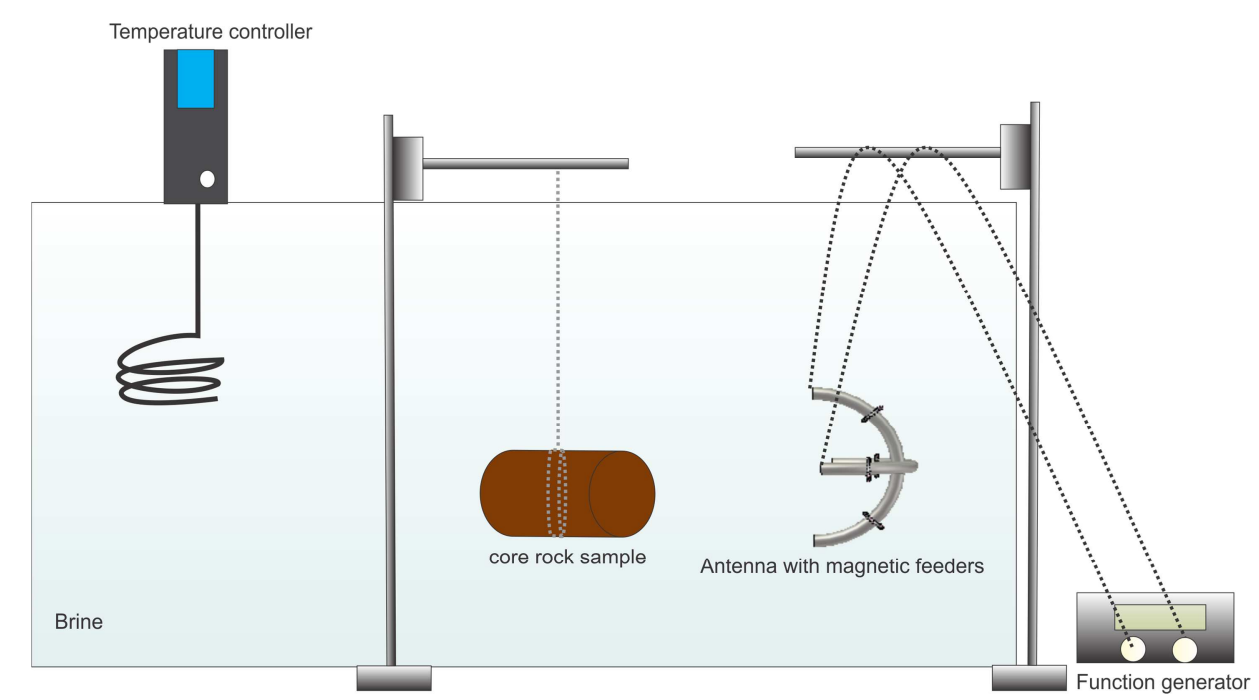

Figure 1. Schematic Diagram of the Experimental Setup. 
A series of experiments were conducted to find the effect of ferrite magnetic feeders by using curve twin dipole antenna, both in air and water. The antenna was placed in the tank and connected with a function generator operated at $1 \mathrm{KHz}$ with square waves and peak to peak voltage of $10 \mathrm{~V}$, both for the antenna and magnetic feeders. Magnetic field strength of the electromagnetic waves was measured by fluxgate magnetic field sensors Model Mag-03MSS100 and the magnetic field data was recorded by Decaport data acquisition system Model NI PXI-1042.

The experimental setup consists of a large water tank. The tank has a surface area of $1.82 \mathrm{~m} \times$ $0.91 \mathrm{~m}$, and depth of $0.61 \mathrm{~m}$. A conductive environment was created by filling the entire tank with water. The aluminum curve twin dipole EM antenna was used as the source. Three receivers were placed in the water tank at the height of $25 \mathrm{~cm}$ from the bottom of the scale tank. The square wave with $10 \mathrm{~V}$ peak to peak and $1 \mathrm{KHz}$ frequency was applied to the antenna by a function generator. The EM antenna was towed at the height of $35 \mathrm{~cm}$ from the bottom of the scale tank. The antenna was moved towards and away from the three receivers. Magnetic field produced by the EM antenna was detected by fluxgate magnetic field sensor Mag-03MSS100.

For EOR application, core samples were characterized using Poroperm System to measure the permeability and porosity. Two core samples with different properties such porosity and permeability were saturated with brine. A crude oil from Angsi I-35 field with viscosity $3.37 \mathrm{cp}$ and density $0.815 \mathrm{~g} / \mathrm{cc}$ was injected at a flow rate of $2 \mathrm{ml} / \mathrm{min}$ using Benchtop Permeator System. After the core samples had been saturated with oil, the volume of the original oil in place (OOIP) was noted. Then water flooding was performed to obtain oil in place. These core samples with oil were placed in the tank with brine to replicate the reservoir environment. An aluminum curve twin dipole antenna with magnetic feeders was used to provide the electromagnetic waves. This antenna was connected to a function generator operating with square waves at $50 \mathrm{MHz}$ and peak to peak voltage of $10 \mathrm{~V}$. A temperature regulator was used to regulate the brine temperature at $55^{\circ} \mathrm{C}$, which is the reservoir temperature. Oil volume recovered after the electromagnetic waves treatment was measured by Dean-Stark extraction method. The duration for the extraction was 24 hour.

\section{Nanofluid Preparation}

Cobalt nanoparticles were mixed with three different concentrations of stabilizer, $0.1 \%, 0.5 \%$ and $1 \%$. The stabilizer used in this experiment is Sodium Dodecyl Sulphate (SDS). Then, these samples were placed in an ultrasonic bath for 2 hours. After that, the samples were left for a month, and observation was made every week to observe which of the combination has higher suspension layer. After a month, the mixture with $1 \%$ Sodium Dodecyl Sulphate has the highest suspension, therefore this mixture was chosen for further experiments throughout this work. Another experiment was conducted by injecting the nanofluid into the glass beads sample in the PVC column which is exposed to the EM waves for 24 hours as shown in Fig. 2 Finally the percentage of oil recovery was calculated.

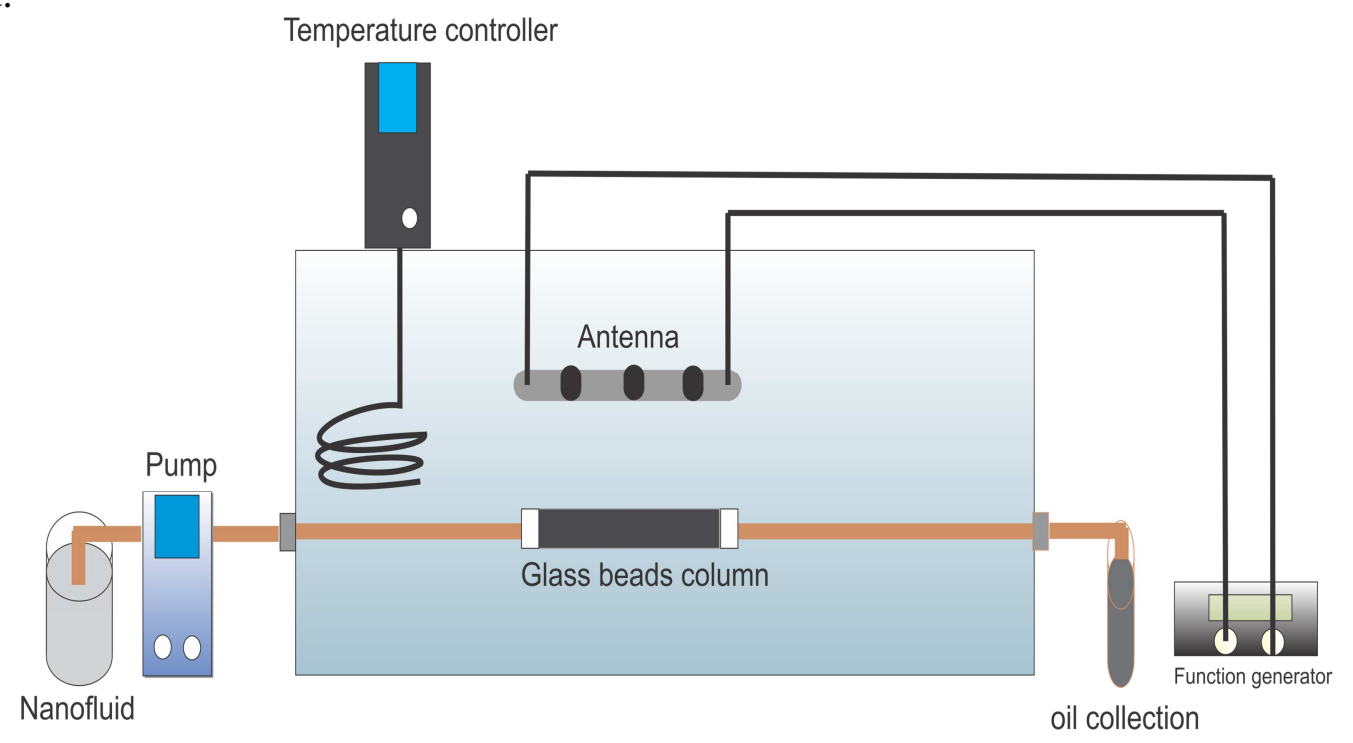

Figure 2. Schematic diagram experiment setup for nanofluid EOR. 


\section{Results and Discussion}

\section{Cobalt ferrite nanoparticles}

Fig.3 shows the XRD patterns of cobalt ferrite $\left(\mathrm{CoFe}_{2} \mathrm{O}_{4}\right)$ nanoparticles prepared at sintering temperatures of $600^{\circ} \mathrm{C}$ and $800^{\circ} \mathrm{C}$. The major peak [311] shows the cubic structure of cobalt ferrite $\left(\mathrm{CoFe}_{2} \mathrm{O}_{4}\right)$ at the sintering temperature of $600^{\circ} \mathrm{C}$ and $800^{\circ} \mathrm{C}$.

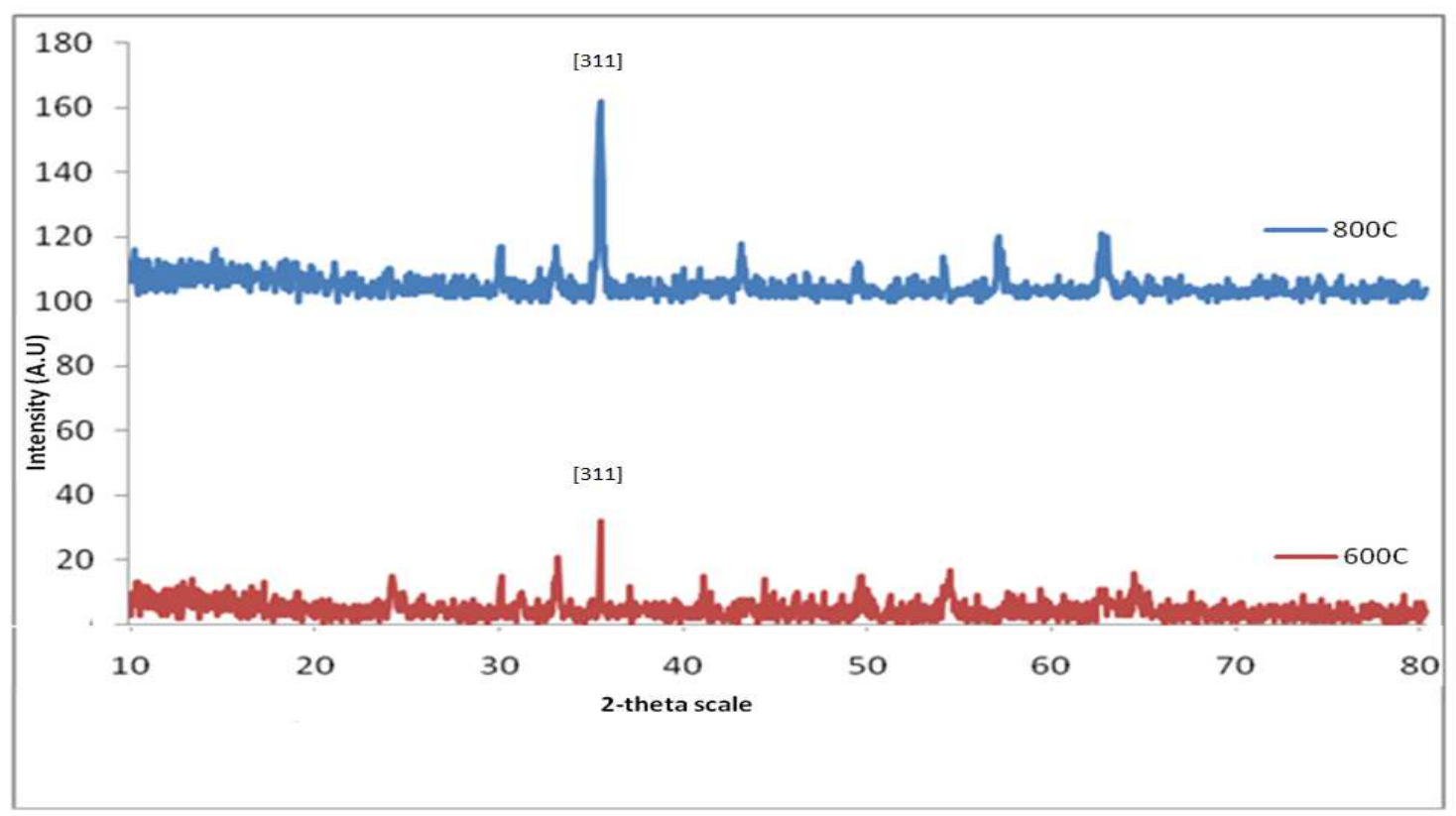

Figure 3. XRD Pattern for Cobalt Ferrite with [311] peak with annealed at temperature $600^{\circ} \mathrm{C}$ and $800^{\circ} \mathrm{C}$.

From Scherer formula, it is calculated that the crystallite size increases from $51.17 \mathrm{~nm}$ to $62 \mathrm{~nm}$ by increasing the annealing temperature from $600^{\circ} \mathrm{C}$ to $800^{\circ} \mathrm{C}$.

The morphology of the samples was observed by Field Emission Scanning Electron Microscope (FESEM). The morphology for Cobalt Ferrite $\left(\mathrm{CoFe}_{2} \mathrm{O}_{4}\right)$ annealed at $600^{\circ} \mathrm{C}$, and $800^{\circ} \mathrm{C}$ is shown in Fig. 4 and Fig. 5, respectively.

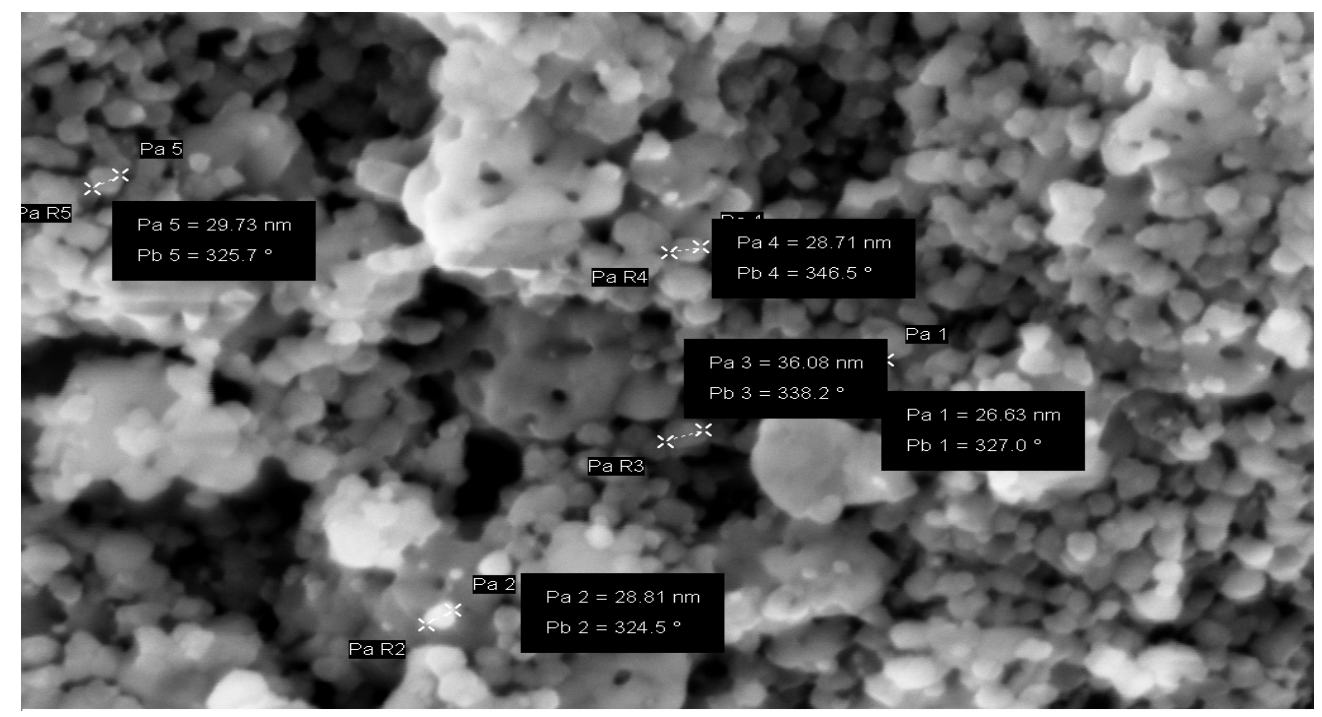

Figure 4. Field Emission-Scanning Electron Microscope (FESEM) image of Cobalt Ferrite, $\mathrm{CoFe}_{2} \mathrm{O}_{4}$ annealed at $600^{\circ} \mathrm{C}$.

It was observed from the micrograph of sample annealed at $600^{\circ} \mathrm{C}$, the grain size is in the range of $26 \mathrm{~nm}$ to $36 \mathrm{~nm}$. The second sample which was annealed at $800^{\circ} \mathrm{C}$, the grain size is in the range of $60 \mathrm{~nm}$ to $127 \mathrm{~nm}$. 


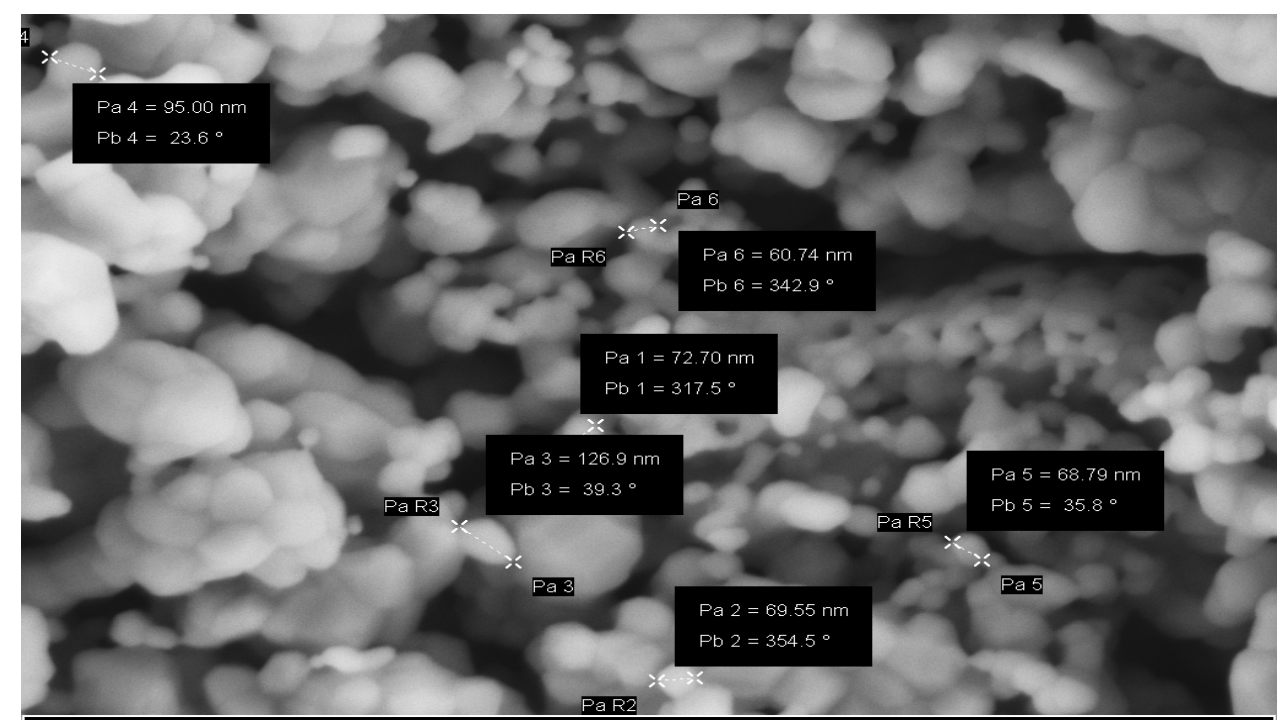

Figure 5. Field Emission-Scanning Electron Microscope (FESEM) image of Cobalt Ferrite, $\mathrm{CoFe}_{2} \mathrm{O}_{4}$ annealed at $800^{\circ} \mathrm{C}$.

Energy Dispersive X-Ray (EDX) is a chemical microanalysis technique performed with FESEM. The EDX data and standard deviation for cobalt ferrite $\left(\mathrm{CoFe}_{2} \mathrm{O}_{4}\right)$. The EDX results of $\mathrm{CoFe}_{2} \mathrm{O}_{4}$ shows that the cobalt, iron and oxygen elements are with atomic percentage of $9.79 \%, 24.70 \%$ and $65.41 \%$ respectively at $600^{\circ} \mathrm{C}$. Similarly EDX results at $800^{\circ} \mathrm{C}$ shows that the cobalt, iron and oxygen elements are with atomic percentage of $10.86 \%, 26.52 \%$ and $62.62 \%$ respectively.

The experimental atomic values were compared with theoretical atomic values. Cobalt ferrite sample annealed at $800^{\circ} \mathrm{C}$ was chosen because it has lower standard deviation for $\mathrm{Co}, \mathrm{Fe}$, and $\mathrm{O}$ which are $24 \%, 7.18 \%$ and $9.59 \%$, respectively.

From Fig.6 it is observed that initial permeability increases as frequency increases. While, relative loss factor (RLF) decreases as the frequency increases. Grain size would affect directly magnetic properties of soft ferrites [21]. All ferrites have higher relative loss factor (RLF) at lower frequencies $(\mathrm{kHz})$ range, which may be due to higher hysteresis loss arising from their porous structures (Fig. 7) [22]. The result also shows that the Q-factor increases as the frequency increases, but is starts to decrease at one point (Fig.8). According to [23-26], Q-factor depends on the microstructure of ferrites for example pore size, grain size, and the presence of second phase.

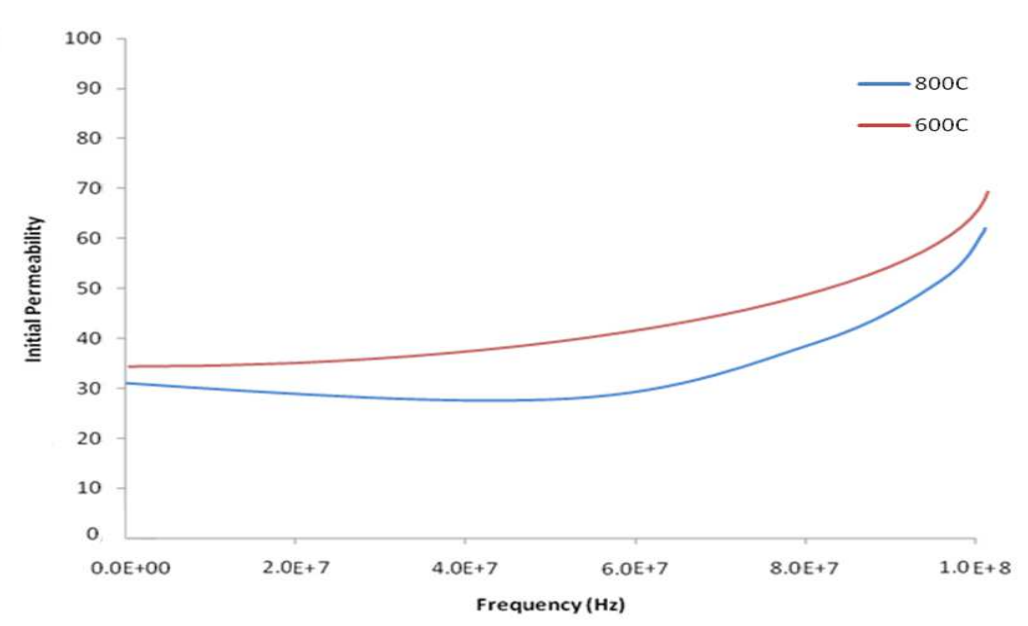

Figure 6. Initial permeability versus frequency for cobalt ferrite toroid. 


\section{Effects of Magnetic Feeders}

When an antenna conductor is inserted in the middle of magnetic feeders, a magnetic flux $(\mathrm{H} \varphi)$ is produced, and this magnetic flux $(\mathrm{H} \varphi)$ induces current to flow along the antenna conductor [27-30].

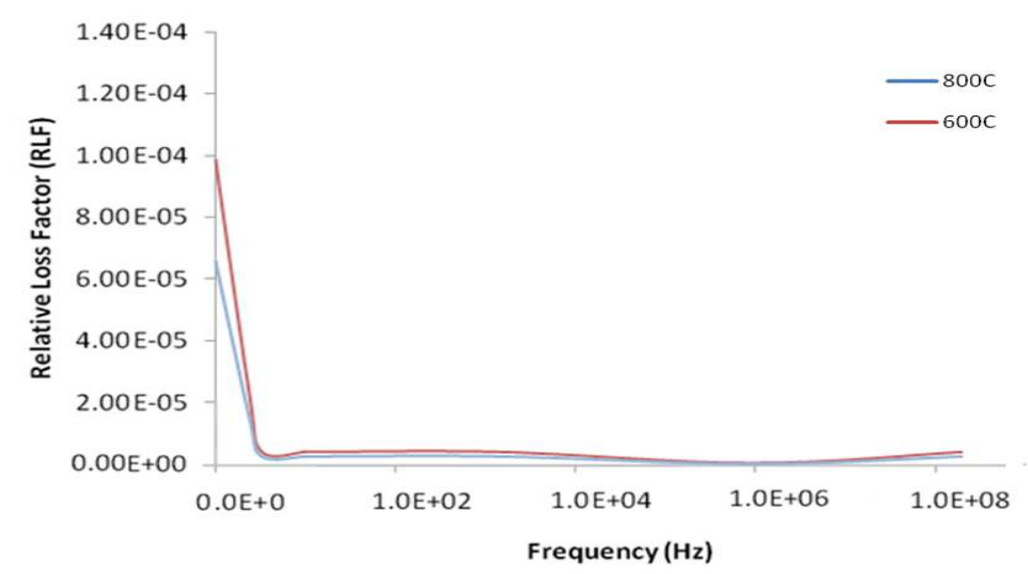

Figure 7. Relative loss factor (RLF) versus frequency for cobalt ferrite.

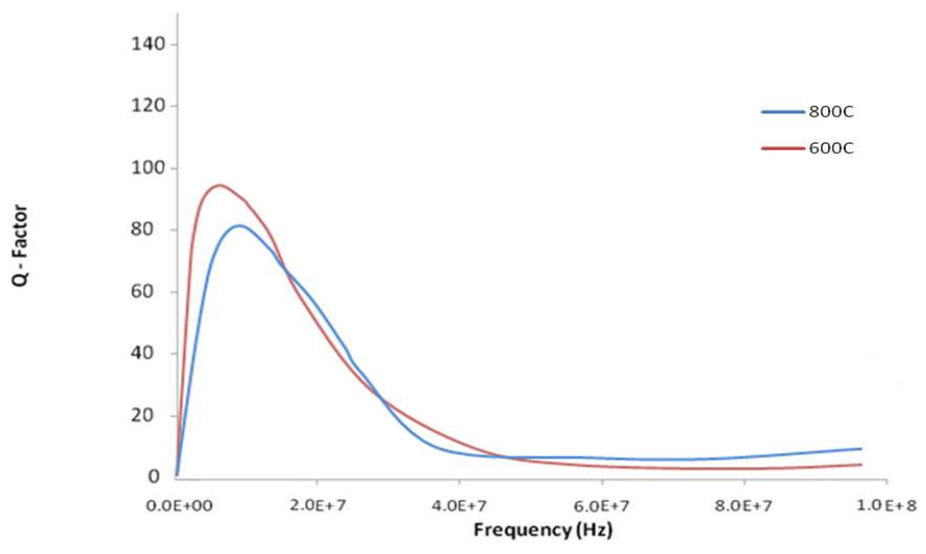

Figure 8. Q-factor versus frequency for cobalt ferrite toroid.

Fig.9 shows the magnetic field strength of EM antenna with and without magnetic feeders in water. From the graph, it is clear that with magnetic feeders, the magnetic field increases as compared to without magnetic feeders [31]. The use of antenna with magnetic feeders increased the magnetic field strength by $0.94 \%$ in water and $5.90 \%$ in air, compared with not using magnetic feeders. The magnetic field increased by $14.40 \%$ in water compared to air when antenna with magnetic feeders was used.

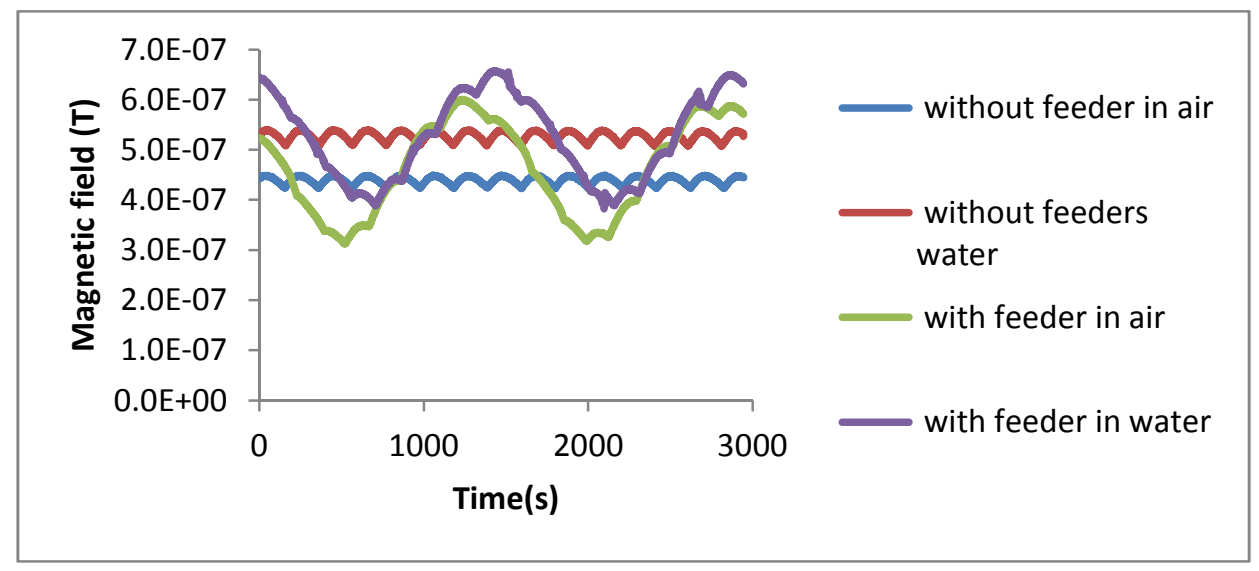

Figure 9. Curve twin dipole antenna with and without magnetic feeders in water and air. 


\section{Magnitude versus Offset (MVO)}

Fig. 10 shows the magnetic field response of three receivers in tap water as a function of source receiver offset. It was found that three receivers recorded the same response of magnetic field. The magnetic field strength of twin dipole antenna with magnetic feeders increased by $275 \%$ as compared to antenna without magnetic feeders [32-35].

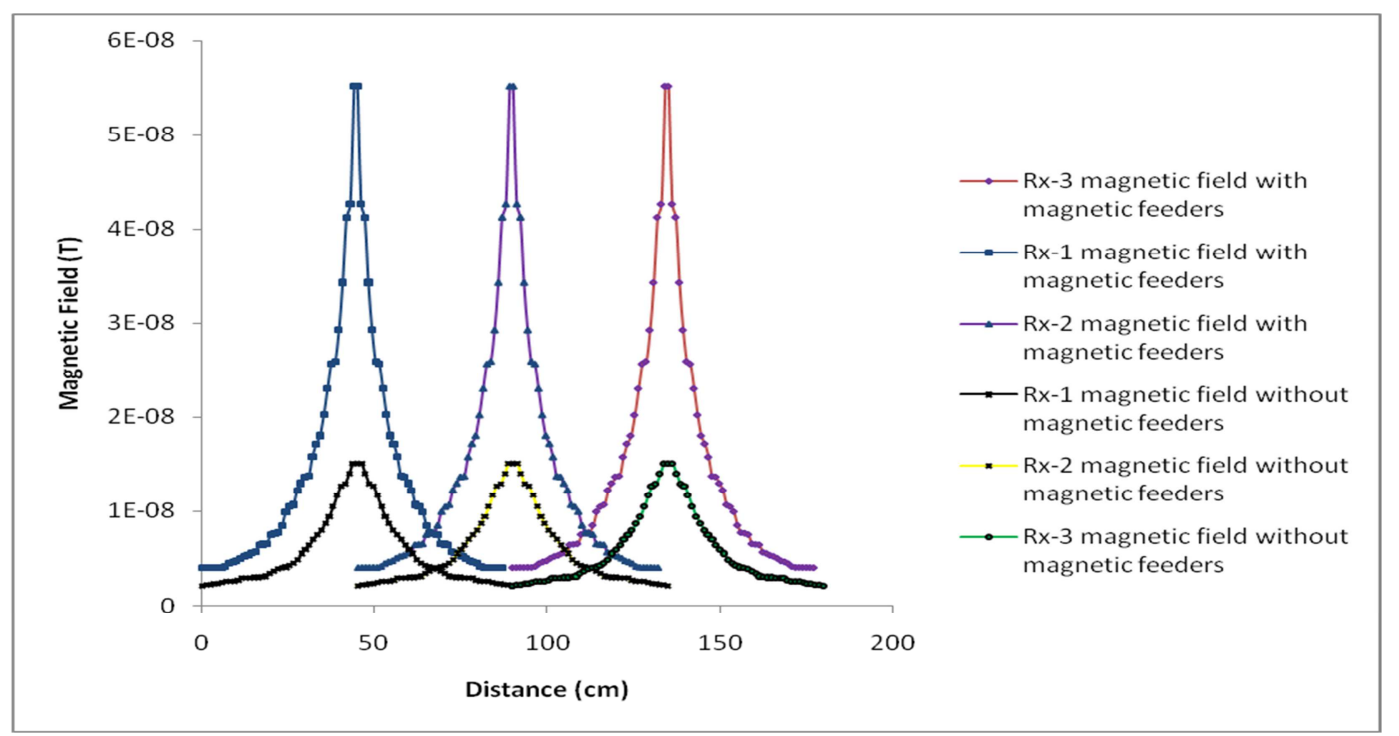

Figure 10. MVO of curve twin dipole antenna with and without magnetic feeders in water.

\section{Oil Recovery by Using Antenna with Ferrite Magnetic Feeders}

The characteristics of the core rock samples measured by He-Porosimeter system are summarized in Table 1 . The core sample labeled A-2 has high porosity and permeability than the sample labeled as A-1.

Table 1. Characteristics of core sample.

\begin{tabular}{cccccc}
\hline $\begin{array}{c}\text { Sample } \\
\text { Name }\end{array}$ & $\begin{array}{c}\text { Core dia } \\
(\mathrm{mm})\end{array}$ & $\begin{array}{c}\text { Core Length } \\
(\mathrm{mm})\end{array}$ & Weight $(\mathrm{g})$ & $\begin{array}{c}\text { Effective Core } \\
\text { Porosity }(\%)\end{array}$ & $\begin{array}{c}\text { Air Permeability } \\
(\mathrm{md})\end{array}$ \\
\hline A-1 & 38.05 & 74.29 & 183.76 & 18.26 & 157.94 \\
A-2 & 38.05 & 75 & 173.04 & 22.10 & 560.90 \\
\hline
\end{tabular}

To analyze the effect of EM waves on oil recovery, experiments were done by using EM antenna with four ferrite magnetic feeders. The core rock samples with oil after water flooding were placed in brine at $5 \mathrm{~cm}$ from the antenna for 24 hours [36].

Table 4 shows the effect of electromagnetic waves on the core samples. The electromagnetic waves passing through the core rock samples were absorbed by water molecules. The absorption of electromagnetic waves raises the temperature of water molecules, which in turn heat up the core samples and hence reduces the oil viscosity. The absorption of the electromagnetic waves in the core sample depends on the material properties of the core rock sample such as dielectric properties. Therefore different materials have different absorbing properties. It was also observed that coalescence of the oil drop from the rock sample started, and these oil drops detached from the core sample. Volume of the remaining oil was determined by Dean Stark extraction method. Table 2 shows the volume of the oil in the core samples before and after exposure to electromagnetic waves, and the percentage of oil recovered. The core sample A-2 has high volume of oil because it has high porosity as shown in Table 1. Porosity is the ratio of void space in the rock to matrix. A high porosity core rock sample will hold more oil and vice versa. 
Table 2 Effects of Electromagnetic Wave Heating for Enhance Oil Recovery.

\begin{tabular}{|c|c|c|c|c|c|}
\hline Sample & $\begin{array}{l}\text { Original oil in } \\
\text { place (OOIP) }\end{array}$ & $\begin{array}{l}\text { Residual Oil in } \\
\text { place (ROIP) } \\
\text { after water } \\
\text { flooding }\end{array}$ & $\begin{array}{l}\text { Dry weight } \\
\text { of the } \\
\text { sample }\end{array}$ & $\begin{array}{l}\text { Weight of the } \\
\text { sample after EM } \\
\text { treatment }\end{array}$ & $\begin{array}{l}\text { Weight of } \\
\text { the oil }+ \\
\text { water }\end{array}$ \\
\hline A-1 & $18 \mathrm{ml}$ & $8.6 \mathrm{ml}$ & $183.76 \mathrm{~g}$ & $192.54 \mathrm{~g}$ & $8.78 \mathrm{~g}$ \\
\hline A-2 & $20.5 \mathrm{ml}$ & $9 \mathrm{ml}$ & $173.04 \mathrm{~g}$ & $182.79 \mathrm{~g}$ & $9.76 \mathrm{~g}$ \\
\hline Sample & \multicolumn{2}{|c|}{ Weight of the oil } & $\begin{array}{l}\text { Volume of } \\
\text { the oil }\end{array}$ & $\begin{array}{l}\text { Volume of the } \\
\text { oil recovered } \\
\text { after EM }\end{array}$ & $\begin{array}{l}\% \text { Recovery } \\
\text { Factor (RF) }\end{array}$ \\
\hline A-1 & \multicolumn{2}{|c|}{$2.68 \mathrm{~g}$} & $3.29 \mathrm{ml}$ & $5.31 \mathrm{ml}$ & $29.50 \%$ \\
\hline A-2 & \multicolumn{2}{|c|}{$3.86 \mathrm{~g}$} & $4.73 \mathrm{ml}$ & $4.27 \mathrm{ml}$ & $20.82 \%$ \\
\hline
\end{tabular}

The core rock sample A-1 gives the recovery of $29.50 \%$ of Original oil in place (OOIP) and the sample A-2 gives the recovery of $20.82 \%$ of Original oil in place (OOIP). The core A-2 has higher porosity, so it has higher original oil in place as compared to sample A-1. Whereas, core sample A-1 contains more water than core sample A-2, therefore sample A-1 give the more recovery as compared to sample A-2.

\section{Oil Recovery Nanofluid Injection With Electromagnetic Waves}

\section{Oil Recovery by Using Nanofluid Injection}

The PVC column packed with glass beads was saturated with brine until a constant pressure was achieved. The flow rate (q), brine density ( $\mu$ ), Length (L), and area (A) of the PVC column were fixed at the following values,

$$
\mathrm{q}=2 \mathrm{ml} / \mathrm{min}, \quad \mu=1.02 \mathrm{cp}, \quad L=22 \mathrm{~cm}, \quad \mathrm{~A}=7.06 \mathrm{~cm}^{2}
$$

The pore/empty space between the glass beads in the PVC column was filled by the brine. By using Darcy formula Eq.3, permeability of the PVC column was calculated.

$$
\text { Permeability }=k=\frac{q \mu L}{A \Delta P}
$$

At a constant pressure (P) of 2.8 Psi or $0.1973 \mathrm{~atm}$, the permeability is $535.81 \mathrm{mD}$. The calculated value of pore volume and porosity is given in Table 3. Permeability is used to measure the ability of any porous media to allow fluids to pass through it. The porosity of any porous media controls the amount of the oil in the porous media.

\begin{tabular}{|c|c|c|c|c|c|}
\hline $\begin{array}{l}\text { Dry weight } \\
\text { ( PVC }+ \\
\text { glass beads) } \\
(\mathrm{g})\end{array}$ & $\begin{array}{l}\text { Wet weight } \\
\text { (PVC }+ \text { glass } \\
\text { beads }+ \\
\text { brine })(\mathrm{g})\end{array}$ & $\begin{array}{c}\text { Pore mass@ brine mass } \\
\text { ( wet weight - dry } \\
\text { weight) }(\mathrm{g})\end{array}$ & $\begin{array}{l}\text { Brine density } \\
(20 \mathrm{kppm} \text { at } \\
\text { room } \\
\text { temperature }) \\
\left(\mathrm{g} / \mathrm{cm}^{3}\right)\end{array}$ & $\begin{array}{l}\text { Pore } \\
\text { volume, } \\
\text { Vv(Brine } \\
\text { mass/brine } \\
\text { density) } \\
\left(\mathrm{cm}^{3}\right)\end{array}$ & Porosity (\%) \\
\hline 487.79 & 536.40 & 48.61 & 1.01 & 48.10 & 30.96 \\
\hline
\end{tabular}

Table 3. Measurement for pore volume. 
Crude oil injection was started when the pressure has stabilised (constant pressure), and was continued until oil drop can be seen on top of the brine collection. The volume of brine displaced from the glass beads packed PVC column will be equal to the volume of crude oil injected into the column. This volume represents the amount of OOIP. For water flooding, brine was injected for a second time until it was confirmed that no more oil dropped from the outlet tube after 24 hours. Some amount of OOIP was displaced by brine during the water flooding. The volume of oil displaced from the column represents the volume of oil recovered from secondary recovery. Nanofluid was injected into the column following the secondary recovery process to simulate EOR process. The experiment was stopped when it was confirmed that no more oil dropped from the outlet tube after 24 hours. The nanofluid injection yielded $8.70 \%$ recovery of oil which was recovered from ROIP.

\section{Oil Recovery using combined method of Nanofluid Injection and Electromagnetic Waves}

For the combined method of electromagnetic waves and nanofluid injection, an electromagnetic wave antenna was placed at $5 \mathrm{~cm}$ above the PVC column. The electromagnetic wave was passed through the PVC column just as the nanofluid was injected into the column. Again, the experiment was stopped when it was confirmed that there was no more oil droplet coming from the outlet tube after 24 hours. The oil recovery obtained by using this method is $31.58 \%$ of ROIP.

Table 4 tabulates the OOIP, and the percentages of oil recovery by nanofluid injection and combined method of nanofluid injection and electromagnetic waves. From nanofluid injection experiment, the percentage of oil recovered is $8.70 \%$ while from nanofluid injection with electromagnetic waves experiment, the percentage of oil recovered is $31.58 \%$. The combined method i.e. nanofluid injection with electromagnetic waves shows an improvement in oil recovery by $22.88 \%$ over nanofluid injection alone. Metal oxide nanoparticles was used as viscosity reducing agent because they can reduce the percentage of polar coumpounds in the oil by decrease hydrogen bonding[17,37]. Using magnetic nanoparicles in nanofluid, it is possible to control their properties and flow in the magnetic field.The viscosity of these magnetic nanofluids are effected by applying the magnetic field which reduces the viscosity of the oil therefore increases the recovery [38]. In the combined method, the cobalt ferrite magnetic nanoparticles are used as the medium to absorb EM waves which contributes to reducing the oil viscosity to improve its flow. This proved that the combined method is able to improve oil flow and better mobility control of reservoir fluids could be achieved.

Table 4 Enhance oil recovery after nanofluid injection with and without electromagnetic wave

\begin{tabular}{cccccc}
\hline & $\begin{array}{c}\text { Original } \\
\text { oil in } \\
\text { place } \\
\text { (OOIP) }\end{array}$ & $\begin{array}{c}\text { Volume of oil } \\
\text { recovered after } \\
\text { water flooding }\end{array}$ & $\begin{array}{c}\text { Residual } \\
\text { oil in place } \\
\text { (ROIP) } \\
\text { after water } \\
\text { flooding }\end{array}$ & $\begin{array}{c}\text { Oil } \\
\text { recovered } \\
\text { after } \\
\text { nanofluid } \\
\text { injection }\end{array}$ & $\begin{array}{c}\text { Percentage } \\
\text { Recovery } \\
\text { Factor (RF) }\end{array}$ \\
\hline $\begin{array}{c}\text { Nanofluid Injection } \\
\text { Nanofluid Injection } \\
\text { with } \\
\text { electromagnetic } \\
\text { waves }\end{array}$ & $46 \mathrm{ml}$ & $34.50 \mathrm{ml}$ & $11.50 \mathrm{ml}$ & $1 \mathrm{ml}$ & $8.70 \%$ \\
\hline
\end{tabular}

\section{Conclusions}

Single phase cobalt ferrite $\left(\mathrm{CoFe}_{2} \mathrm{O}_{4}\right)$ nanoparticles synthesized via sol- gel method have been used as an injection fluid for oil recovery. Cobalt ferrite nanoparticles annealed at while for the sample annealed at $800^{\circ} \mathrm{C}$, the particle size is $62 \mathrm{~nm}$ as determined by XRD and 60nm as determined by FESEM. The initial permeability of cobalt ferrite powder was found to increase and relative loss factor decreased at high frequency. Antenna with magnetic feeders increases the magnetic field by 
$14.40 \%$ in water compared to antenna in air. Antenna with magnetic feeders increases the magnetic field strength by $0.94 \%$ with respect to no magnetic feeders, in water, and by $5.90 \%$, in air. Magnitude versus offset (MVO) study of antenna with magnetic feeders shows an increase of $275 \%$ in the magnetic field as compared to no magnetic feeders. Antenna with magnetic feeders was able to recover $29.50 \%$ oil from core rock sample A-1 and $20.82 \%$ from core rock sample A-2. Nanofluid injection yielded $8.70 \%$ recovery oil while electromagnetic waves with nanofluid injection yielded a recovery of $31.58 \%$. The cobalt ferrite nanoparticles absorb electromagnetic waves which reduce the oil viscosity and therefore increase oil recovery.

\section{Acknowledgments}

This work was supported by Ministry of Higher Education (MOHE) for the fund provided under FRGS/1/10/TK/UTP/02/29.

\section{References}

[1] M.A. Carrizales, L.W. Lake, and R.T. Johns, 'Multiphase Fluid Flow Simulation of Heavy Oil Recovery by Electromagnetic Heating', SPE 129730, Improved Oil Recovery Symposium. April 24-28, Tulsa, Oklahoma, USA, (2010).

[2] A. Sahni, M. Kumar, and R. B. Knapp, "Electromagnetic heating methods for heavy oil reservoirs," SPE 62550. SPE/AAPG Western Regional Meeting. USA, (2000).

[3] E.R. Rangel-German, J. Schembre, C. Sandberg, A.R. Kovscek, J. Pet. Sci. Eng., 45 (2004)213-23.

[4] O. G. Gunal, and M. R. Islam, J. Pet. Sci. Eng., 26(2000)263-272.

[5] A. B. Chhetri, and M. R. Islam, Pet. Sci. Technol., 26 (2008)1619-1631.

[6] F. Vermeulen and B. McGee, J. Can. Pet. Technol., 39(2000)24-28.

[7] J.E. Bridges, G.C Sresty, H.L. Spencer, and R. A. Wattenbarger, 'Electromagnetic Stimulation of Heavy-Oil Wells'. Paper presented at the Third International Conference on Heavy Crude and Tar Sands. Long Beach, California, USA, (1985).

[8] M.Y. Soliman, J. Pet. Sci. Eng., 18(1997)93-100.

[9] G. C. Sresty, H. Dev, R. H. Snow, and J. E. Bridges, 'Recovery of bitumen from tar sand deposits with the radio frequency process', SPE 10229, Paper presented at the Reservoir Engineering. SPE Annual Technical Conference and Exhibition. October 5-7, San Antonio, TX, USA. (1986).

[10] A. Chakma, and K. N. Jha, "Heavy oil recovery from thin pay zones by electromagnetic heating," SPE Paper 24817, 67th Annual Technical Conference and Exhibition, USA, (1992).

[11] H. Yu, C. Kotsmar, K. Y. Yoon, D. R. Ingram, K. P. Johnston, S. L. Bryant, and C. Huh, 'Transport and Retention of Aqueous Dispersions of Paramagnetic Nanoparticles in Reservoir Rocks' SPE 129887, Paper presented at the Improved Oil Recovery Symposium April 2428, 2010. Tulsa, Oklahoma, USA, (2010).

[12] K.Bhatia, L.Chacko 'Ni-Fe Nanoparticles: An Innovative Approach for Recovery of Hydrates', SPE 143088, Paper presented at the EUROPEC/EAGE Annual Conference and Exhibition. May 23-26, Vienna, Austria, (2011).

[13] S. Ryoo, A. R. Rahmani, K. Y. Yoon, M. Prodanović, C. Kotsmar, T. E. Milner, K. P. Johnston, S. L. Bryant, and C. Huh, 'Theoretical and Experimental Investigation of the Motion of Multiphase Fluids Containing Paramagnetic Nanoparticles in Porous Media',SPE 134879, Paper presented at the SPE Annual Technical Conference and Exhibition. September 19-22, Florence, Italy, (2010).

[14] J. Yu, J. M. Berlin, W. Lu, L. Zhang, A. T. Kan, P. Zhang, E. E. Walsh, S. N. Work, W. Chen, J. M. Tour, M. S. Wong, M. B. Tomson 'Transport Study of Nanoparticles for Oilfield Application',SPE 131158, Paper presented at the International Conference on Oilfield Scale May 26-27,Aberdeen, United Kingdom, (2010). 
[15] P. Zhang, A.T. Kan, C. Fan, S. N. Work, J. Yu, H. Lu, H. A. Al-Saiari, M. B. Tomson, 'Silica-templated Synthesis of Novel Zinc-DTPMP Nanoparticles, Their Transport in Carbonate and Sandstone Porous Media and Scale Inhibition', SPE 130639, Paper presented at the International Conference on Oilfield Scale. May 26-27, Aberdeen, United Kingdom, (2010).

[16] L. Villamizar, P. Lohateeraparp, J. Harwell, D. Resasco, B. Shiau, 'Interfacially Active SWNT/Silica Nanohybrid Used In Enhanced Oil Recovery', SPE 129901, Paper presented at the Improved Oil Recovery Symposium. April 26-28, Tulsa, Oklahoma, USA, (2010).

[17] Shah, D. Rusheet, 'Application of Nanoparticle Saturated Injectant Gases for EOR of Heavy Oils', Paper presented at the International Student Paper Contest at the SPE Annual Technical Conference and Exhibition. October 4-7, New Orleans, Louisiana, USA, (2009).

[18] Z. Li, M. Kawashita, N. Araki, M. Mitsumori, M. Hiraoka, M. Doi, Mat. Sci. Eng. C, 30(2010)990-996.

[19] R. Hergt, W. Andrä, C.G. Ambly, I. Hilger, W.A. Kaiser, U. Richter, H.G. Schmidt, IEEE Trans. Magn., 34(1998),3745-3754.

[20] R.E. Rosensweig, Magn. Magn. Mater. 252(2002)370-374.

[21] M.N. Akhtar, N.Yahya, P. Hussain, International Journal of Basic \& Applied Sciences IJBAS 9(2009)151-154.

[22] S. Zahi, A. R. Daud, and M. Hashim, Mat.Chem.Phys., 106(2007) 452-456.

[23] N. Yahya, R.M.A. Habashi, Krzysztof Koziol, R. Dunin-Borkowski, M.N. Akhtar, M. Kashif and M. Hashim, J. Nanosci. Nanotechno, 11(2011)2652-2656.

[24] N. Yahya, G.K. Hean, American Journal of Applied Sciences 4(2007)80-84.

[25] N. Yahya, K.K.K. Koziol, M.K. Bin Mansor, Defect and Diffusion Forum, 283286(2008)406-412.

[26] W.C. Hsu, S.C. Chen, P.C. Kuo, C.T. Lie, and W.S. Tsai, Mat. Sci. Eng. B, 111,(2004)142149.

[27] F.N. Kong, H. Westerdah, F. Antonsen, 'Excitation of a long wire antenna- Antennas from $200 \mathrm{MHz}$ to $1 \mathrm{~Hz}$, Paper presented at the Tenth International conference on ground Penetrating Radar, June 21-24, Delft, The Netherlands, (2004).

[28] R. W. P. King and G. S. Smith, Antenna in Matter, MIT Press, 1981.

[29] D.S. Jones, Methods in Electromagnetic Wave Propagation Oxford: Clarendon Press, 1979.

[30] C.A. Balanis, Antenna Theory-Analysis and Design, 2nd Edition, John Willy \& Sons, Inc. 1997.

[31] N. Nasir, N. Yahya, M. Kashif, H. Daud, M.N. Akhter, H.M. Zaid, A. Shafie, L.C.Teng, J. Nanosci. Nanotechnol., 11(2011)2551-2554.

[32] N. Nasir, A. Shafie, H. Daud, H.M. Zaid, N. Yahya, M.N. Akhtar, M. Kashif, J. Appl. Sci., 11(2011)1309-1314.

[33] M.N. Akhtar, N. Yahya, N. Nasir, "Novel EM antenna based on $\mathrm{Y}_{3} \mathrm{Fe}_{5} \mathrm{O}_{12}$ magnetic feeders for improved MVO", Saudi International Electronics, Communications and Photonics Conference, Saudi Arab, (2011).

[34] M.N. Akhtar, N. Yahya, K. Koziol, N. Nasir, Ceram. Int., 37(2011)3237-3245.

[35] N. Yahya, T.W. Zhu, Development of $\mathrm{Y}_{3} \mathrm{Fe}_{5} \mathrm{O}_{12}$ nano-magnetic feeder for EM source of an intelligent horizontal twin dipoles, AIP Conference Proceedings, 1136(2009)269-276.

[36] M. Kashif, N. Yahya, H.M. Zaid, A. Shafie, M. Jasamai, N. Nasir, M.N. Akhter, J. Appl. Sci., 11 (2011)1366-1370.

[37] B. Hascakir, T. Babadagli, S. Akin, Field-Scale Analysis of Heavy-Oil Recovery by Electrical Heating, SPE 117669, International Thermal Operations and Heavy Oil Symposium, October 20-23, Calgary, USA, (2008).

[38] S. Odenbach, Colloids and Surfaces A: Physicochem. Eng. Aspects, 217 (2003) 171-178. 